\title{
BLUME: DESENVOLVIMENTO DE UM MOBILIÁRIO EVOLUTIVO DE DORMIR PARA CRIANÇAS DO PRIMEIRO SETÊNIO BASEADO NO ESTUDO DA ANTROPOSOFIA
}

\author{
Ana Maria Trebbi Berton \\ Universidade Presbiteriana Mackenzie \\ ana.berton@gmail.com
}

Resumo: O presente artigo foi originado do Trabalho de Conclusão de Curso de Graduação em Design da Universidade Presbiteriana Mackenzie. O projeto, apresentado neste artigo, teve por objetivo desenvolver um design baseado em alguns dos principais conceitos da Antroposofia, método de ciência que aborda o ser humano, a natureza, o universo e o espiritualismo desenvolvida pelo filósofo Rudolf Steiner no século XX. A partir da identificação de um público alvo e um problema inicial no estudo realizado, foi desenvolvido o projeto de um mobiliário evolutivo para dormir voltado a crianças de 0 a 7 anos, com o intuito de aplicar os benefícios da antroposofia por meio do design.

Palavras Chave: Design, Antroposofia, Crianças, Dormir, Mobiliário.

\begin{abstract}
This article was originated from the coursework for the completion of the Degree in Design at the Mackenzie Presbyterian University. The project presented in this paper, aimed to develop a design based on some of the key concepts of anthroposophy; scientific method developed by the philosopher Rudolf Steiner in the twentieth century that addresses the human being, nature, the universe and spiritualism. After identifying a target audience and an initial problem during the study, the project of an evolving furniture to sleep was developed focused on children of 0-7 years in order to apply the benefits of anthroposophy through the design.
\end{abstract}

Keywords: Design, anthroposophy, Children, Sleep, Furniture. 


\section{INTRODUÇÃO}

O presente artigo foi realizado a partir do trabalho de conclusão do curso de Design da Universidade Presbiteriana Mackenzie em junho de 2016, onde se projetou um mobiliário de design inovador, evolutivo para crianças de zero a sete anos dormirem, que acompanha o seu crescimento. O projeto foi desenvolvido baseado na Antroposofia, de acordo com Valdemar W. Setzer (2014), um método de ciência que aborda o ser humano, a natureza, o universo e o espiritualismo.

A Antroposofia foi desenvolvida pelo filósofo austríaco Rudolf Steiner no início do século XX após o profundo estudo sobre as obras de Johann Wolfgang Von Goethe, filósofo romancista e dramaturgo alemão do século XVIII, que abordavam as formas de vida e suas origens. A Antroposofia se aplica em diversas áreas como pedagogia, arquitetura, agricultura e medicina, apresentando método próprio e ampliando o conhecimento adquirido pelo método científico convencional.

Os objetivos deste projeto incluem: utilizar a estética antroposófica como base para a sua composição; tornar os benefícios da Antroposofia, por meio do design, parte do cotidiano do ser humano desde os primeiros anos de vida; usar materiais que estejam adequados a estes princípios; desenvolver modelos volumétricos com estudo antropométrico, estético e funcional; ajudar difundir a antroposofia.

Segundo Rudolf Steiner e a Antroposofia, a jornada do homem na terra, bem como as características que desenvolve ao longo dela, pode ser dividida em períodos de sete anos que são denominados de setênios. O primeiro setênio é para a Antroposofia um dos mais importantes na vida do ser humano, pois é quando começa a ter conhecimento sobre o próprio corpo e desenvolver as capacidades de falar, andar e pensar. Como diretrizes do projeto foram consideradas estas características, além das principais atividades diárias e as necessidades de comer, brincar e dormir da criança. A atividade "dormir" foi explorada como foco principal, uma vez que criança para se desenvolver bem, passa em seus primeiros anos mais horas dormindo do que acordada.

Seguindo a metodologia de Bruno Munari (2008), o desenvolvimento do projeto iniciou-se com uma pesquisa sobre o tema e com a análise de suas diversas áreas, buscando delimitá-lo e diagnosticar um problema inicial.

O estudo, portanto, foi realizado baseado em bibliografias sobre Antroposofia e o processo de desenvolvimento de crianças sob este ponto de vista. Entre a bibliografia estudada estão presentes os livros: "Noções Básicas da Antroposofia" de Rudolf Lanz, "Os três primeiros anos da criança" e "O desenvolvimento dos Sentidos e a Experiência Corporal" de Karl König, o livro "Desvendando o crescimento: As fases evolutivas da infância e da adolescência" de Bernard Lievegoed e algumas das palestras Rudolf Steiner.

Para a compreensão dos conceitos estudados de forma prática, foram realizadas conversas com pessoas da comunidade antroposófica, como pais, educadores e psicólogos. Também foram feitas visitas a berçários e jardins de infância de pedagogia antroposófica.

Durante a fase criativa e prática do projeto foram realizados estudos de formas e cores, thumbnails, sketches, estudo ergonômico com modelo volumétrico em escala real e estudo de sistemas e materiais a partir da modelagem 3D e da confecção de modelo volumétrico em escala reduzida. 


\section{DIRETRIZES PARA O DESENVOLVIMENTO DE UM MOBILIÁRIO PARA A CRIANÇA DO PRIMEIRO SETÊNIO DORMIR: DESENVOLVIMENTO DA CRIANÇA, OS SENTIDOS E A ESTÉTICA ANTROPOSÓFICA}

\subsection{Desenvolvimento da criança.}

O presente projeto pretende adequar um mobiliário para a criança do primeiro setênio dormir, de acordo com as fases de seu desenvolvimento propostas por Zeller (apud LIEVEGOED,1994 , p. 19): recém-nascido, criança pequena e transições, representadas no Quadro 1.

Quadro 1 - Fases do desenvolvimento da criança, características e necessidades.

\begin{tabular}{|c|c|c|c|}
\hline Fase & Idade & Características & Necessidades \\
\hline Recém-nascido & 0 a 2 anos & $\begin{array}{l}\text { - Frágil, indefeso e } \\
\text { temeroso. } \\
\text {-Aprendizado das } \\
\text { capacidades de andar e falar }\end{array}$ & $\begin{array}{l}\text {-Proteção } \\
\text {-Acolhimento } \\
\text { - Transição gradativa do } \\
\text { ambiente interior materno } \\
\text { para o mundo. }\end{array}$ \\
\hline $\begin{array}{l}\text { Transição para fase } \\
\text { da criança pequena }\end{array}$ & 2 a 4 anos & $\begin{array}{l}\text { - Aprimoramento das } \\
\text { capacidades de falar e andar } \\
\text {-desenvolvimento da } \\
\text { capacidade de pensar. }\end{array}$ & $\begin{array}{l}\text { - Movimentar-se } \\
\text { livremente }\end{array}$ \\
\hline Criança Pequena & 4 a $5^{1} / 2$ anos & $\begin{array}{l}\text {-Desenvolvimento da } \\
\text { capacidade criativa e da } \\
\text { imaginação } \\
\text { - Brinca de forma } \\
\text { descompromissada. }\end{array}$ & $\begin{array}{l}\text { - Brincar com objetos } \\
\text { simples } \\
\text { - Evitar brinquedos } \\
\text { plásticos e com imagens } \\
\text { prontas que possam } \\
\text { prejudicar sua capacidade } \\
\text { de criar }\end{array}$ \\
\hline $\begin{array}{l}\text { Transição para a } \\
\text { Idade Escolar }\end{array}$ & $5^{1} / 2$ a 7 anos & $\begin{array}{l}\text { - Primeiro estirão } \\
\text { - brinca de modo mais } \\
\text { intencional e menos } \\
\text { fantasiosamente }\end{array}$ & $\begin{array}{l}\text { - Brincar com objetos } \\
\text { simples } \\
\text { - Evitar brinquedos } \\
\text { plásticos e com imagens } \\
\text { prontas que possam } \\
\text { prejudicar sua capacidade } \\
\text { de criar }\end{array}$ \\
\hline Idade Escolar & $\begin{array}{l}\text { A partir dos } 7 \\
\text { anos }\end{array}$ & $\begin{array}{l}\text {-Troca dos dentes } \\
\text { - brincadeiras intencionais e } \\
\text { objetivas }\end{array}$ & $\begin{array}{l}\text { - Ruptura do ambiente } \\
\text { excessivamente maternal }\end{array}$ \\
\hline
\end{tabular}

Fonte: Elaborado pelo autor com base em Zeller (apud LIEVEGOED,1994.)

Para os recém-nascidos, como foi observado em uma visita ao "Berçário Abraço" de pedagogia Waldorf em São Paulo, os berços são cobertos por dois tecidos, um azul e outro magenta. A combinação desses dois tecidos leva a uma cor arroxeada que simula a cor interna do útero materno, conferindo a ela um ambiente mais familiar. Isso faz com que ela se sinta mais acolhida e menos insegura, proporcionando a criança uma transição, ao exterior materno, mais gradativa. Essa é uma prática bastante comum, utilizada fora da antroposofia também, e foi considerada para o projeto. Na Escola Warldorf Franscisco de Assis foi encontrado algo semelhante. Cabanas de madeira cobertas por tecido de cor magenta são dispostas nas salas de jardim de infância para as crianças brincarem. 


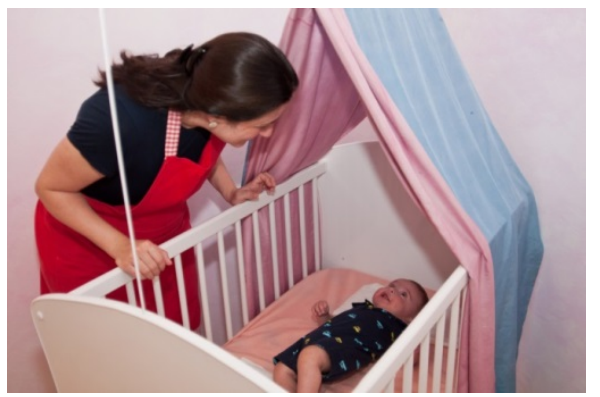

Figura 1 - Berço no Berçário Abraço.

Fonte: Site do Berçário Abraço. Disponível na internet por http em: <http://literature.org/authors/carroll-lewis >. Acesso em 9 mar. 2016

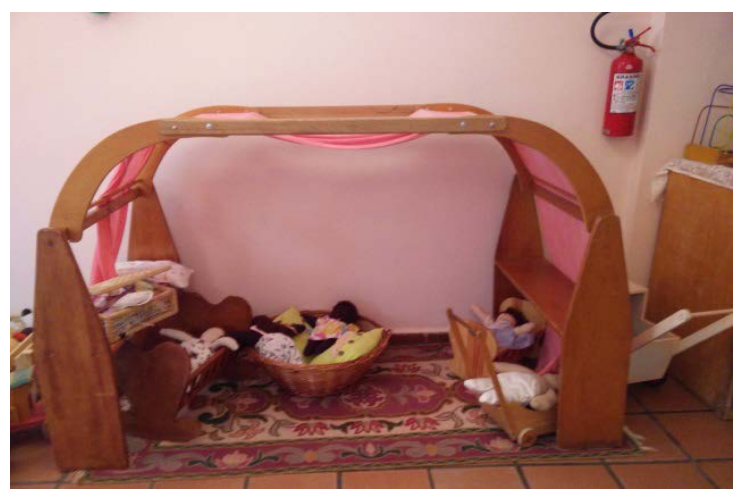

Figura 2 - Cabana de brincar

Fonte: Elaborada pelo autor com base na pesquisa realizada

Para o período em que a que a criança começa a erguer-se e movimentar-se, foi considerada a possibilidade de oferecer-Ihe um ambiente em que ela possa exercer os movimentos de modo mais livre e encontre estabilidade para erguer-se. Esse é o período em que a criança desenvolve uma imaginação criativa bastante ativa, então foi pensado também como o mobiliário poderia estimular a sua imaginação.

Quando a criança estiver atingindo a idade escolar e, com isso, certo grau de maturidade, ela não precisará mais de um ambiente tão fechado e maternal e o mobiliário poderá ser mais aberto.

De acordo com Lanz (2005 p.33) e a Antroposofia: "[...] durante o sono ocorre uma separação da parte anímico espiritual da parte físico-etérica. Aliviado da consciência, das sensações da vida anímica, o corpo descansa na cama, reduzido ao nível de uma planta, pois aparenta apenas funções vegetativas". A partir dessa afirmação foi considerada essa comparação, do ato de dormir com a condição de uma planta, como diretriz estética deste projeto.

\subsection{Os Doze Sentidos}

Durante os setênios o ser humano se apropria e desenvolve seus sentidos. Dentro do pensamento antroposófico, o ser humano desenvolve ao todo doze (ao invés de cinco) sentidos: do tato, sentido vital, do movimento, do equilíbrio, do olfato, do paladar, da visão, do calor, da audição, da palavra, do pensamento e do Eu. Os doze podem ser divididos em três níveis de desenvolvimento denominados de básicos, médios, e superiores. Cada nível de desenvolvimento contém quatro sentidos e todos 
os sentidos são desenvolvidos logo nos primeiros anos de vida da criança, porém, são aprimorados ao longo dos três primeiros setênios como disposto no Quadro 2:

Quadro 2 - Os doze sentidos, níveis de desenvolvimento e características.

\begin{tabular}{|c|c|c|c|}
\hline Nível dos Sentidos & Sentidos & $\begin{array}{c}\text { Setênio de } \\
\text { desenvolvimento }\end{array}$ & Características \\
\hline Básicos ou inferiores & $\begin{array}{c}\text { Tato, vital, movimento } \\
\text { e equilíbrio }\end{array}$ & Primeiro Setênio & $\begin{array}{c}\text { Vinculados ao corpo e } \\
\text { suas experiências }\end{array}$ \\
\hline Médios & $\begin{array}{c}\text { Olfato, paladar, visão e } \\
\text { do calor }\end{array}$ & Segundo Setênio & $\begin{array}{c}\text { Vinculados às } \\
\text { experiências sensoriais } \\
\text { e influências do mundo }\end{array}$ \\
\hline Superiores & $\begin{array}{c}\text { Audição, da palavra, do } \\
\text { pensamento e do Eu }\end{array}$ & Terceiro Setênio & $\begin{array}{c}\text { Vinculados ao mundo } \\
\text { espiritual e à cognição }\end{array}$ \\
\hline
\end{tabular}

Fonte: Elaborado pelo autor, com base em Karl König (2000)

Sendo os sentidos básicos os que mais se desenvolvem durante a primeira fase de vida da criança, a seguir será disposto cada um deles e como poderá ser trabalhado dentro do projeto.

De acordo com o médico e escritor Karl König (2000), o primeiro sentido que a criança desenvolve, logo ao nascer, é o sentido do tato que proporciona uma série de experiências sensoriais envolvendo lembranças, despertando sensações vivenciadas anteriormente, além de proporcionar a vivência dos limites corporais e de distinguir onde termina o próprio corpo e começa o limite do que esta sendo tocado. Para o projeto, esse sentido pode ser explorado logo nos primeiros dias de vida do bebê por meio de um ambiente que o envolva e permita que perceba os próprios limites corporais tocando esse ambiente que o abraça, podendo estimular sua memória através do sentido tátil, lembrando-o do interior materno.

O segundo sentido descrito por König (2000) é o sentido vital, concentrado principalmente no sistema nervoso simpático, é percebido quando o ser humano não se sente bem ou se sente incomodado, com fome, sede ou frio, sendo principalmente pautado na respiração, nutrição e aquecimento. Para o projeto, o móvel deve proporcionar conforto e aquecimento para a criança.

O sentido do movimento próprio traz ao ser humano a noção de corporalidade, a criança passa a localizar os próprios membros e perceber os próprios movimentos. Este projeto, em um primeiro momento é acolhedor e fechado, deve transitar para proporcionar a criança um ambiente em que ela possa exercer seus movimentos de modo mais livre para a sua percepção sobre seus membros e os movimentos.

O último dos sentidos básicos mencionado por König (2000) é o sentido do equilíbrio. Está vinculado com uma série de processos sensoriais na manutenção do equilíbrio. Órgãos como ouvidos e olhos, assim como os sentidos do tato e do movimento próprio participam do sentido do equilíbrio por meio de reflexos e instintos. Considerando o sentido do equilíbrio para o projeto, foi pensado em proporcionar ao bebê um leve balançar simulando o interior da mãe, mantendo a mesma sensação de equilíbrio que ele possuía antes de nascer. Isso pode garantir uma transição mais suave para o exterior materno, evitando a sensação de tontura causada pela interrupção do movimento que ele sentia antes do nascimento. Outra questão a ser considerada é, antes do primeiro ano de idade, proporcionar à criança um espaço 
estável para que ela possa exercitar a força que precisa adquirir para erguer-se e poder andar quando estiver acordada.

\subsection{Estética Antroposófica: Arquitetura e Design}

De acordo com o arquiteto Michael Mösch (1998), a arquitetura antroposófica, apresenta como principal característica, formas orgânicas buscando passar a ideia de vida através da sensação de movimentos. Apresenta, ao invés de planos retos e lapidados, formas arredondadas e curvas que dão continuidade entre os elementos de sua estrutura, sendo próprias de uma forma de vida. De acordo com ele, as formas utilizadas na composição de um espaço podem influenciar na qualidade da atividade exercida nele.

O conceito de organicidade, vida e movimento entre os elementos na composição de estrutura, foi adotado como uma das diretrizes para a composição estética do presente projeto de design, onde buscou-se unir as necessidades da criança e a atividade de dormir a este princípio estético que guia a arquitetura antroposófica. Foi pensado no uso de geometrias suaves, orgânicas e sequenciais buscando evitar uma estrutura carregada de formas aleatórias que pudessem desviar o foco da criança na hora de dormir.

\subsection{Resultado final - Blume}

A proposta final do projeto, denominada BLUME, conta com um sistema que permite a sua regulagem e adaptação em 3 fases, acompanhando o crescimento da criança.

O nome BLUME vem do alemão e significa "flor", remetendo à forma como o mobiliário abre-se e ao desabrochar da criança durante os primeiros sete anos de vida.

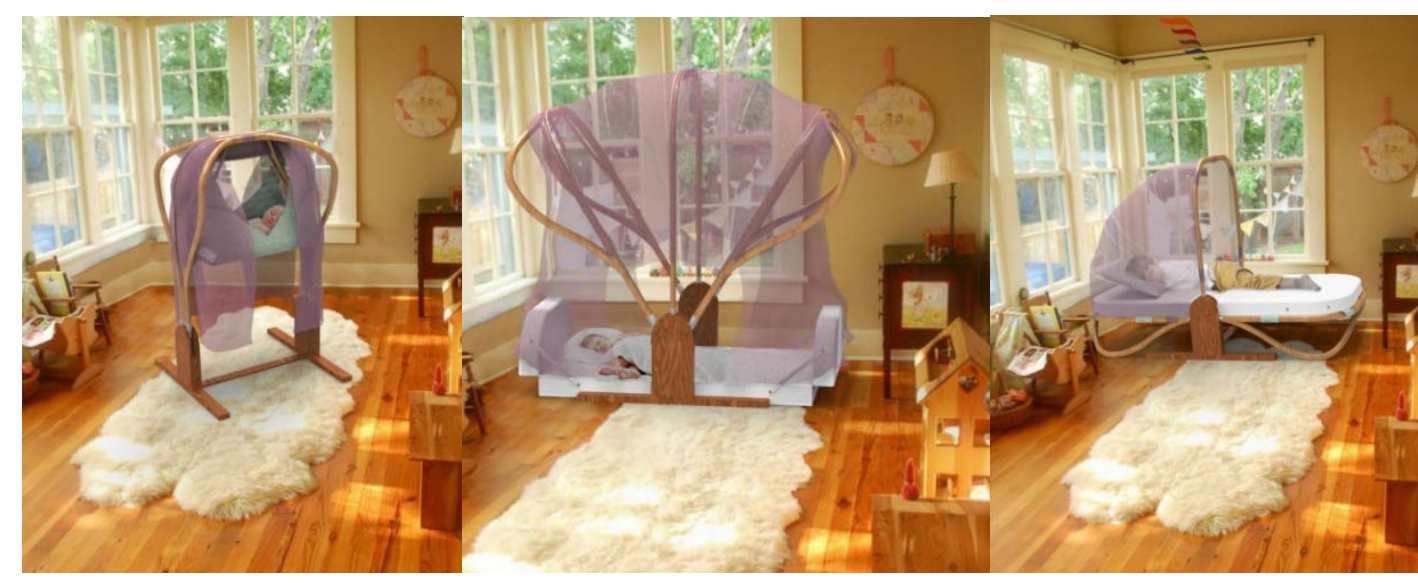

Figura 3 - Sequencia de renders do BLUME aplicado.

Fonte: Elaborada pelo autor com base na pesquisa realizada

\subsubsection{Fase 1 (0 A 5 Meses)}

O mobiliário BLUME nessa fase permanece fechado, oferecendo proteção e aconchego necessários ao recém nascido. 


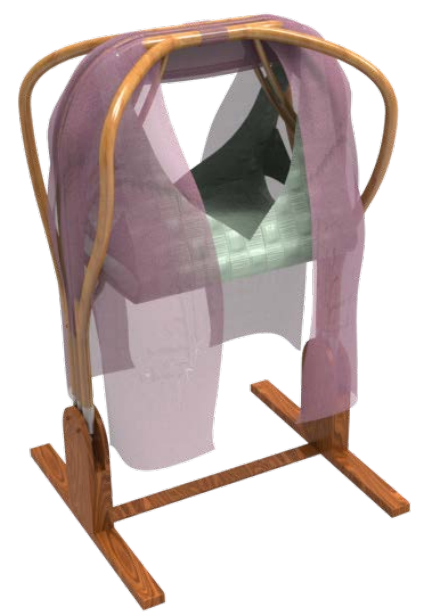

Figura 4 - Render da fase 1 do BLUME

Fonte: Elaborada pelo autor com base na pesquisa realizada

O Moisés de tecido é disposto a uma altura ergonômica para os pais colocarem e retirarem o bebê. Este é preso a estrutura com velcro e pode ser facilmente removido. Cavilhas dispostas na estrutura impedem que o Moisés escorregue por ela.

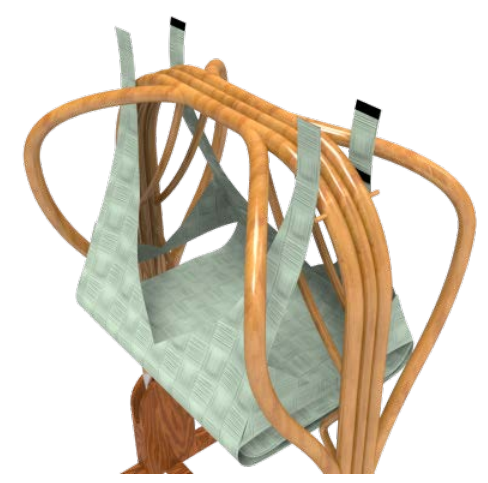

Figura 5 - Render do Moisés do BLUME

Fonte: Elaborada pelo autor com base na pesquisa realizada

A criança pode tocar as extremidades do tecido que a envolve, e estimular o sentido do tato. Devido à sua maleabilidade é possível embalar a criança.

A cor do véu, disposto sobre a estrutura e preso por velcro, é o resultado das cores azul e magenta e simula a cor do útero materno.

\subsubsection{Fase 2 (5 meses a 4 anos)}

Para a segunda fase, a estrutura é parcialmente aberta. Abre-se o toldo de tecido, fechado na fase anterior, e posiciona-se o colchão adaptado no chão ao centro da estrutura. Esta disposição simula a estrutura de uma cabana, estimulando a imaginação da criança. 


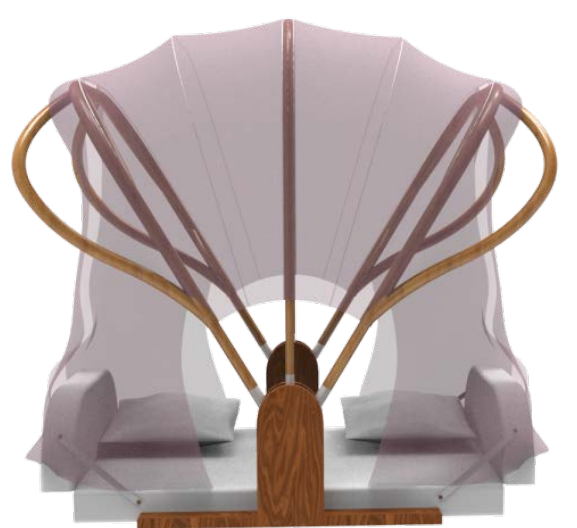

Figura 6 - Render da fase 2 do BLUME

Fonte: Elaborada pelo autor com base na pesquisa realizada

O mecanismo presente no interior da estrutura permite sua abertura e regulagem.
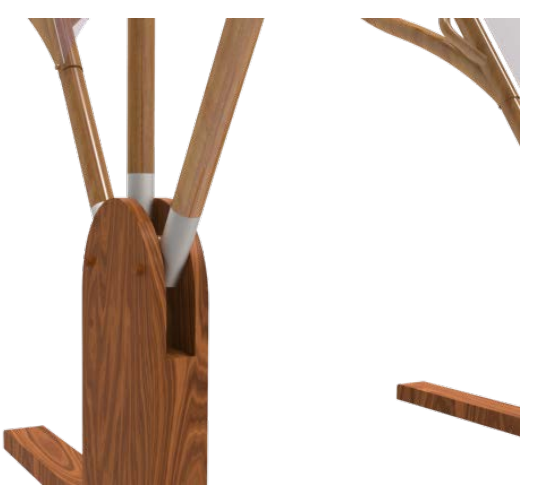

Figura 7 - Render da base do BLUME

Fonte: Elaborada pelo autor com base na pesquisa realizada

Com o colchão no chão, a criança encontra estabilidade para erguer-se, movimentar-se e estimular seus sentidos de modo seguro. As laterais do colchão podem ser erguidas e abaixadas, limitando e ampliando o espaço da criança.

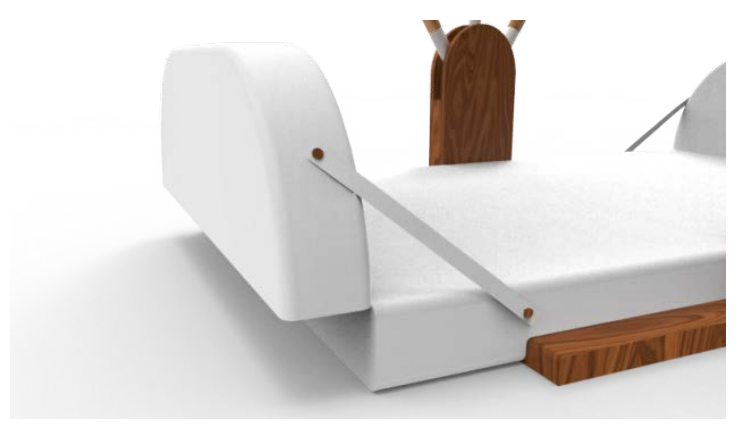

Figura 8 - Render do Colchão do BLUME com as laterais erguidas

Fonte: Elaborada pelo autor com base na pesquisa realizada

\subsubsection{Fase 3 ( 4 a 7 anos)}

Na terceira fase do BLUME, a estrutura é retraída e aberta completamente, passando a ter a forma mais convencional de cama. 


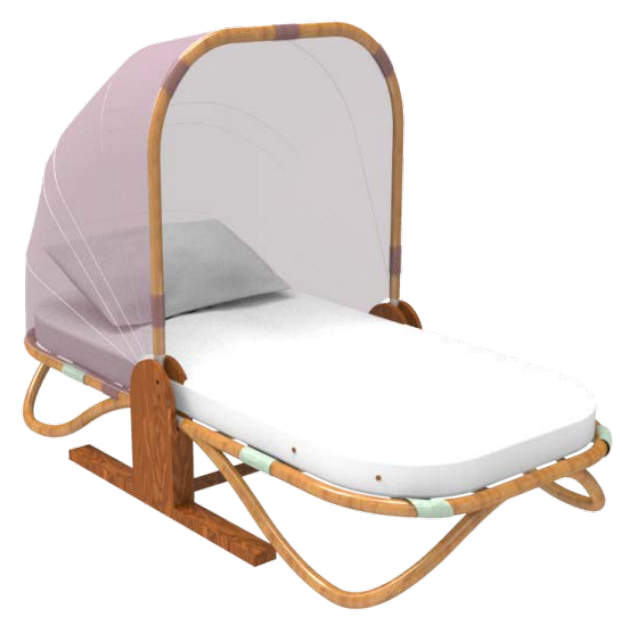

Figura 9 - Render da fase 3 do BLUME

Fonte: Elaborada pelo autor com base na pesquisa realizada

O tecido usado como Moisés na primeira fase, passa a integrar a estrutura de sustentação do colchão, evitando seu descarte.

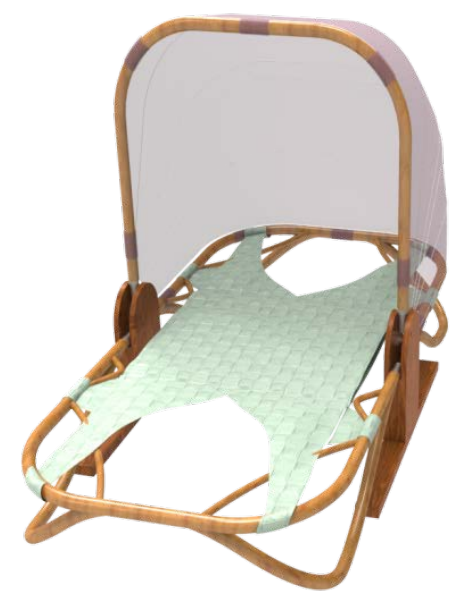

Figura 10 - Render do Moisés como suporte para o colchão na fase 3

Fonte: Elaborada pelo autor com base na pesquisa realizada

O toldo de tecido, preso por velcro, pode ser removido e a estrutura tubular central pode ser abaixada.

$O$ véu presente nas fases 1 e 2 é removível.

\subsubsection{Componentes, dimensões e materiais.}

A adaptação em três fases do mobiliário evolutivo para dormir BLUME, confere a ele três dimensões distintas.

Fase 1 - Altura: $1500 \mathrm{~mm}$ Largura: 940,4 mm Profundidade: $910 \mathrm{~mm}$

Fase 2 - Altura: $1500 \mathrm{~mm}$ Largura: 940,4 mm Profundidade: $1590 \mathrm{~mm}$

Fase 3 - Altura: 1300 mm Largura: 940,4 mm Profundidade: $1960 \mathrm{~mm}$

O mobiliário é basicamente composto por uma estrutura principal, uma base, um Moisés, um colchão e um toldo. 


\section{- Estrutura principal e base}

Para a estrutura principal e base do BLUME, pensou-se na utilização de madeira maciça, material bastante utilizado na Antroposofia que prioriza o uso de materiais não sintéticos.

A estrutura principal do BLUME seria composta por madeira maciça em formato tubular da espécie Teca, madeira resistente e flexível. Em seu processo de produção é curvada à quente por sistema de autoclave e molde.

Para a base, pensou-se na utilização de chapas de madeira maciça da espécie Imbuia que se encaixam por meio de cavilhas, facilitando a sua montagem e desmontagem. $O$ design proposto permite a sustentação e rotação da estrutura.

Pés niveladores encontram-se nas extremidades da base do mobiliário, permitindo sua fácil adaptação a ambientes desnivelados.

\section{- Moisés}

Feito em tecido de algodão, material não sintético bastante utilizado em produtos para crianças por ser antialérgico. Sua base, onde a criança deita na primeira fase, é estofada para proporcionar maior sustentação, conforto e estabilidade.

O tecido usado como Moisés na primeira fase também é utilizada na terceira para auxiliar a estrutura principal a sustentar o colchão. Em suas extremidades, há faixas de velcro para facilitar sua colocação e remoção da estrutura, assim como sua adaptação da primeira à terceira fase (figuras 5 e 10).

\section{- Toldo}

O toldo é composto por uma estrutura de arame de aço e tecido de tule que se expande conforme a abertura da estrutura principal. Ele é fixado à estrutura por faixas de tule e velcro (figuras 4,6 e 9).

Fase 1 - Altura: $844.6 \mathrm{~mm}$ Largura: $900 \mathrm{~mm}$ Profundidade: $108 \mathrm{~mm}$

Fase 2 - Altura: $906 \mathrm{~mm}$ Largura: $900 \mathrm{~mm}$ Profundidade: $1274.6 \mathrm{~mm}$

Fase 3 - Altura: $992.8 \mathrm{~mm}$ largura: $900 \mathrm{~mm}$ profundidade: $980 \mathrm{~mm}$

\section{- Colchão}

O colchão é feito em Poliuretano expandido, de densidade D28 e seu design permite sua adaptação entre as fases. $\mathrm{Na}$ segunda fase do mobiliário, para proporcionar maior segurança à criança, suas laterais são erguidas e presas por faixas de tecido e botões de madeira e podem ser facilmente liberadas e abaixadas.

Com as laterais levantadas - Altura: 400 mm Largura: 700 mm Profundidade: $1500 \mathrm{~mm}$

Com as laterais abaixadas - Altura: $100 \mathrm{~mm}$ largura: $820 \mathrm{~mm}$ profundidade: $1840 \mathrm{~mm}$

\section{- Sistema de abertura e regulagem}

O sistema de regulagem de altura e abertura é constituído por molas de metal, botões externos de madeira, botões internos e buchas de aço que se encontram no interior da estrutura principal e da base. As buchas são utilizadas para garantir o funcionamento do sistema sem que haja o desgaste da madeira assim como o mau funcionamento pela sua dilatação ou contração. 


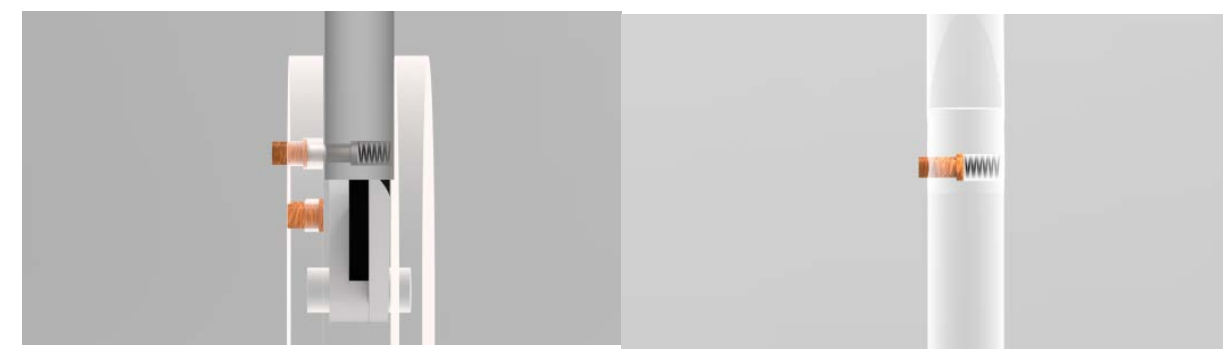

Figura 11 - Render do sistema de molas para regulagem abertura e altura da estrutura Fonte: Elaborada pelo autor com base na pesquisa realizada

O mecanismo presente na base, desenvolvido para a rotação das estruturas tubulares, permite a abertura em fases e total do mobiliário.
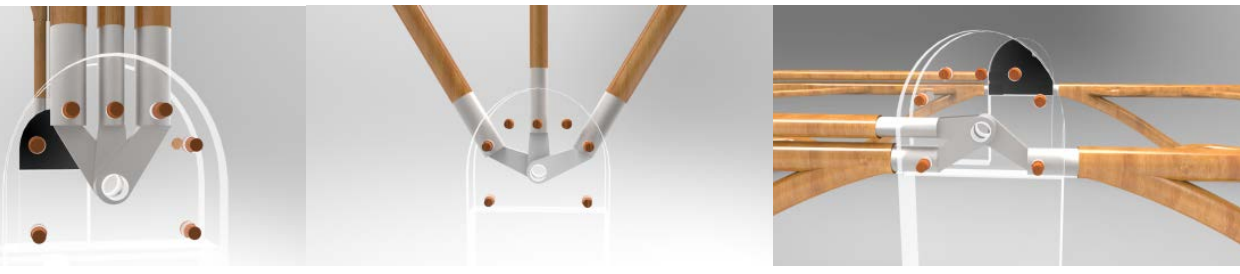

Figura 12 - Render do mecanismo de abertura nas três fases do mobiliário.

Fonte: Elaborada pelo autor com base na pesquisa realizada

\section{CONCLUSÃO}

A Antroposofia, por meio de suas teorias, busca contribuir para o desenvolvimento saudável e equilibrado do ser humano respeitando a ordem natural de suas experiências e necessidades. Por meio deste projeto, foi possível compreender como o design pode aplicar as suas teorias e contribuir com esse tipo de desenvolvimento.

O projeto do Blume é capaz de proporcionar à criança em seu primeiro setênio de vida, além de um sono saudável seguindo os conceitos da antroposofia, uma experiência sensorial que ajuda em seu crescimento, adequando-se a ela conforme as características e necessidades que vai adquirindo ao longo destes anos.

O projeto de design do Blume, também mostra como é possível a adaptação de um mobiliário sem o descarte de qualquer componente de modo simples e mais sustentável.

\section{REFERÊNCIAS}

ABMA. O ser humano segundo a antroposofia. Disponível na internet por http em: <http://www.abmanacional.com.br/index.php?link=8\&id=15>. Acesso em 19 fev. 2016.

ASSOCIAÇÃO TRAVESSIA, O que é antroposofia. Disponível na internet por http em: $<$ http://www.associacaotravessia.org.br/html/antroposofia.html >. Acesso em $14 \mathrm{dez}$. 2015.

KÖNIG, Karl. O Desenvolvimento dos Sentidos e a Experiência Corporal. São Paulo: Sociedade Brasileira de Médicos Antroposóficos, 2000. 
LANZ, Rudolf. Noções Básicas de Antroposofia. São Paulo: Editora Antroposófica, 2005.

LIEVEGOED, Bernard. Desvendando o crescimento: As fases evolutivas da infância e da adolescência. São Paulo: Editora Antroposófica, 1994.

MÖSCH, Michael. Arquitetura Antroposófica: as artes plásticas e o desenvolvimento da alma humana. Chão Gente, Botucatu, n. 30, p. 12 - 15, mai. 1998.

SEBBEN, Derblai. A importância do sono e a pedagogia. 28 de nov. de 2014. Disponível na internet por http em: <http://www.micael.com.br/blog/paracompartilhar/>. Acesso em 3 mar. 2016.

SETZER, Valdemar. 0 que é a Antroposofia. 18 de mai de 2014. Disponível na internet por http em: <https://www.ime.usp.br/ vwsetzer/antrop/o-que-eh-antroposofiameu-site.html>. Acesso em 11 mai. 2016.

SOCIEDADE ANTROPOSÓFICA NO BRASIL. Antroposofia. Disponível na internet por http em: <http://www.sab.org.br/portal/antroposofia2>. Acesso em 17 dez. 2015.

SOCIEDADE ANTROPOSÓFICA NO BRASIL. Arquitetura, Introdução. Disponível na internet por http em: <http://www.sab.org.br/portal/arquitetura/159-introducaoarquitetura>. Acesso em 11 jan. 2016.

SOCIEDADE ANTROPOSÓFICA NO BRASIL. Biografia de Rudolf Steiner. Disponível na internet por http em: <http://www.sab.org.br/portal/antroposofia2/biografia-derudolf-steiner>. Acesso em 14 dez. 2015.

SOCIEDADE ANTROPOSÓFICA NO BRASIL. Histórico no Mundo. 17 de jun. de 2009

Disponível na internet por http em: <http://www.sab.org.br/portal/antroposofia2/nomundo>. Acesso em 14 dez. 2015.

STEINER, Rudolf. Os Doze Sentidos e Os Sete Processos Vitais. São Paulo: Editora Antroposófica, 2012.

UTESCHER, Eliane. Biblioteca Virtual da Antroposofia. Resumo do Desenvolvimento do Ser Humano através dos 9 setênios. 15/07/2013. Disponível na internet por http em: $<$ http://www.antroposofy.com.br/wordpress/resumo-do-desenvolvimento-do-serhumano-atraves-dos-9-setenios/>. Acesso em 11 jan. 2016. 